\title{
Martillos y Clavos: UnA Respuesta a "Normas PENAles Y CONFlicto DE Deberes", de Juan Pablo Alonso
}

Iñigo Ortiz de Urbina Gimeno*

* Universitat Pompeu Fabra
Sumario: I. Introducción: martillos, clavos y parsimonia. II. El sistema del juez cuando en el sistema del ciudadano se da una colisión de deberes. III. La concreta resolución del conflicto. IV. Observación final.

\section{INTRODUCCIÓN: MARTILLOS, CLAVOS Y PARSIMONIA}

Según un dicho popular en el ámbito de las políticas públicas, si la única herramienta de la que uno dispone es un martillo, tenderá a ver todos los problemas como clavos. Trasladada al terreno intelectual, la enseñanza subyacente a esta declaración nos advierte sobre los problemas que puede causar el empeño por extender el 
uso de una herramienta teórica más allá del ámbito donde ésta es ventajosa. Un martillo es una herramienta extremadamente útil cuando uno pretende insertar clavos, pero no lo es cuando quiere cortar madera o extraer tornillos: para estas otras tareas hay herramientas más eficientes. El problema mencionado aqueja la contribución de Juan Pablo Alonso, "Normas penales y conflicto de deberes". En ella se utiliza el sofisticado instrumental conceptual de la teoría analítica del Derecho para identificar y resolver un problema jurídico-penal. Se trata, sin embargo, de un problema que ya está identificado y resuelto dogmáticamente, y resulta además que está resuelto a satisfacción incluso del propio Alonso, quien tras un largo rodeo iusfilosófico finalmente aplica la institución dogmática-penal de la colisión de deberes sin conectar tal aplicación con el análisis iusfilosófico previo.

En estas condiciones, entiendo perfectamente legítimo que, ante el artículo de Alonso, el jurista penal lleve a cabo una argumentación similar a ésta: "Se explican dos nociones de deber jurídico, la distinción entre norma primaria y secundaria en Kelsen y la diferencia entre el sistema primario, o del juez, y el secundario, del ciudadano (apartado 1); se determinan los sistemas del juez y del ciudadano en el supuesto concreto (apartados 2 y 3 ); se comparan ambos sistemas, mostrando sus divergencias (apartado 4). Después de todo ello, sin embargo, en el apartado decisivo a efectos penales (apartado 5: ‘Condena o absolución?’), el autor aplica la institución dogmática de la colisión de deberes, sin vincularla con el resto del análisis. ¿Para qué entonces ha servido éste?"

En este punto comienza mi preocupación. La teoría analítica del Derecho es una compleja pero fecunda forma de elaboración conceptual $^{1}$. En su aplicación en el campo penal, sin embargo, tiene una

\footnotetext{
${ }^{1}$ No voy a entrar en la discusión sobre la oportunidad de referirse a una parte de la elaboración filosófica en general y iusfilosófica en particular como "analítica" (para una excelente discusión, v. GLOCK 2008). Para los efectos limitados de este artículo nos valdrá con entender que en el ámbito iusfilosófico esta denominación se reserva para una perspectiva que se caracteriza por la importancia que otorga a "explicitar las conexiones lógicoformales y epistemológicas de los enunciados que utiliza el teórico del derecho (...) pulir y mantener limpios los conceptos que utilizamos y precisar las reglas que nos permiten combinarlos a fin de evitar el peligro de la confusión y la falacia" (GARZÓN VALDÉS 2000: 12).
} 
dura competidora en la dogmática desarrollada sobre la base de la teoría jurídica del delito, una teoría de la imputación altamente sistematizada y profundamente analítica (en un sentido coloquial del término, referido a la elaboración teórica basada en la descomposición de los conceptos en sus partes integrantes). Buena parte de los penalistas, aunque desde luego no todos, ven la teoría analítica del Derecho como algo prescindible. Ello se debe a que entre los penalistas prevalece una excelente opinión acerca de las posibilidades de la teoría jurídica del delito, frecuentemente considerada la parte "noble" del Derecho penal académico y, de nuevo según el sentir mayoritario entre los penalistas, una de las obras cumbre de toda la elaboración teórica en Derecho (MIR 1987: 180; DíEz RIPOLLÉS 1998: 51). Así las cosas, entre los penalistas es común la sospecha de que es poco o más bien nada lo que a la elaboración jurídico-penal puede aportar la teoría analítica del Derecho (o, en general, cualquier otra teoría distinta de la teoría jurídica del delito de cuño alemán).

La contribución de Juan Pablo Alonso da pábulo a este tipo de razonamiento. Se introducen conceptos y distinciones, en ocasiones complejos, pero finalmente se resuelve el problema acudiendo a la teoría jurídica del delito. ¿Por qué entonces no acudir directamente a ella y olvidarse de la teoría analítica del Derecho? El castellano de mi país se refiere a este tipo de situaciones afirmando lacónicamente que "para este viaje no hacen falta alforjas". Con un lenguaje más sofisticado, la moderna filosofía de la ciencia habla del "principio de parsimonia" o, en términos más clásicos, de la "navaja de Ockham". Expresado concisamente, este criterio de decisión entre teorías nos indica que, entre dos teorías con el mismo contenido explicativo, ha de preferirse aquella que lo haga con menor uso de recursos conceptuales ${ }^{2}$. En el caso que nos ocupa, el problema jurídico-penal descrito por Alonso es fácilmente identificable como un supuesto de colisión de deberes, sin necesidad de acudir a ninguna de las distinciones ofrecidas por el autor, y es así mismo

${ }^{2}$ En general sobre los criterios de decisión entre teorías, v. THAGARD (1978, passim, esp. 79-89). Sobre el principio de parsimonia, v. DOMÈNECH (1998: 139140). Para una aplicación específica en el ámbito del Derecho penal, la decisión entre diversas teorías sobre la conceptualización de la relación entre tipicidad y antijuridicidad, v. ORTIZ DE URBINA (2008: 24-26). 
resoluble acudiendo a teorías dogmáticas al uso, de nuevo sin tener que pasar por los conceptos y distinciones propuestas. ¿Qué ganamos con el utillaje conceptual propuesto? ¿Por qué no limitarnos a la teoría jurídica del delito si es ésta la que finalmente decide la cuestión?

Pero quizás estoy siendo injusto con Alonso. A fin de cuentas, el objeto de su trabajo no es, o no sólo es, solventar una cuestión penal. En la p. 25 de su trabajo tal objeto se describe, en términos más amplios, como el análisis de las relaciones entre el "sistema del juez" y el "sistema del ciudadano" en el ámbito del Derecho penal, explorando la patología (en el sentido de falta de correspondencia entre ambos sistemas) que se produce cuando el sistema del ciudadano presenta conflictos entre deberes jurídico-penales. Sin embargo, también esta distinta definición del objeto de la indagación me genera dudas.

En primer lugar, al penalista ha de explicársele por qué esta exploración tiene algún tipo de interés para él. Ello no resulta en absoluto evidente cuando se tiene en cuenta que al penalista ya le resulta poco fructífero explorar la patología inicialmente estudiada por Alchourrón y Bulygin a la que alude Alonso, aquella que se produce por la existencia de lagunas normativas en el sistema del ciudadano. Tal supuesto no es interesante para el penalista dado que, por la actuación de la regla de clausura en la que consiste el principio de legalidad penal, la existencia de lagunas normativas en el sistema del ciudadano no provoca ninguna disfunción al juez, puesto que si no se dan todos los presupuestos de la condena éste necesariamente ha de absolver. Ciertamente, la falta de interés de la cuestión para el penalista es contingente a la subsistencia del principio de legalidad y sus dos principales corolarios, las garantías criminal y penal. Pero esa existencia es y ha sido un presupuesto de la labor jurídico-penal al menos durante los 150 últimos años, probablemente el presupuesto más fundamental, de modo que la indagación de las consecuencias de su eventual inexistencia no puede en absoluto considerarse una prioridad ${ }^{3}$.

\footnotetext{
${ }^{3}$ Por el contrario, sí es prioritario prestar atención al hecho de que, a pesar de su reconocimiento generalizado, estas dos garantías no pasan por su mejor momento. Especialmente preocupante es la relajación de la interdicción de la retroactividad penal desfavorable y el desdibujo de la distinción entre penas y medidas de seguridad. Sobre el primer tema, puesto negro sobre blanco por
} 
En segundo lugar, la exploración que en concreto desarrolla Alonso parte de una inadecuada especificación de los sistemas del juez y del ciudadano. Una más completa especificación de ambos -en el caso cuyo análisis se nos propone- muestra que entre ellos no existen divergencias. Alonso no lo percibe porque su análisis indebidamente excluye de ambos sistemas el juego de las normas que establecen eximentes. En términos jurídico-dogmáticos al uso: porque su análisis se limita a la tipicidad, sin incluir el del resto de las categorías de la teoría jurídica del delito, y muy en especial las normas que eximen de responsabilidad ${ }^{4}$. Ciertamente, Alonso resuelve limpiamente la contradicción por él detectada utilizando la colisión de deberes 5 . Pero lo hace después de entender que tal contradicción existe, y ello sólo es cierto bajo su particular reconstrucción de los sistemas del juez y del ciudadano.

la última línea jurisprudencial del TS español sobre el cómputo de beneficios penitenciarios, v. CUERDA (2006); sobre el segundo, v. ROBINSON (2008: capítulo 6).

${ }^{4}$ En adelante me referiré prioritariamente a las normas que prevén causas de justificación, porque tanto Alonso como yo entendemos que la colisión de deberes funciona en el caso como causa de exclusión de la antijuridicidad. Dependiendo del problema concreto que se quiera analizar, sin embargo, la correcta construcción del sistema del juez puede exigir la consideración de otras causas de exclusión de la sanción, dado que su existencia (sean causas de exclusión de la antijuridicidad, de la culpabilidad o de la punibilidad) obliga al juez a absolver.

${ }^{5}$ Como es sabido, mientras que parte de la doctrina considera que en la colisión de deberes el sujeto siempre resulta justificado si no se decide por el deber de menor rango (esto es, si cumple el de mayor rango o cualquiera de los dos, si son de igual rango), para otro sector doctrinal la colisión entre deberes del mismo rango tiene carácter exculpante y no justificante. No me queda claro cuál es la posición de Alonso. Si bien parece apuntar a la primera postura, citando con aprobación la opinión de Roxin, al mismo tiempo en la p.56 afirma que "El padre de dos hijos que en un naufragio debe optar entre salvar a un hijo o a otro actúa antijurídicamente (aunque sin culpa) respecto del hijo que no salva, porque aunque no tiene la posibilidad fáctica de salvar a ambos, tiene la posibilidad teórica de hacerlo". Sin embargo, en el caso que se cita, que es el que Roxin pone como ejemplo canónico de colisión de deberes, de seguir la primera opinión doctrinal el padre estaría justificado, por haber cumplido con un deber del mismo rango que el omitido (esto es, por cierto, lo que afirma RoxIN 2006: 779-783). 
En lo que sigue mostraré que la especificación de los sistemas del juez y el ciudadano que realiza Alonso es inadecuada (apartado II). A continuación mostraré que también lo es su aplicación de la institución dogmática de la colisión de deberes al caso concreto (apartado III). Concluiré con una sucinta reflexión final (apartado IV).

\section{EL SISTEMA DEL JUEZ CUANDO EN EL SISTEMA DEL CIUDADANO SE DA UNA COLISIÓN DE DEBERES}

Como explica Alonso, un subconjunto de normas primarias regula la actividad sancionadora del juez respecto a un concreto universo de discurso. En el apartado 2 de su artículo Alonso restringe el universo de discurso al juego de los artículos $176.3^{\circ}$ y $302.1^{\circ}$ y nos muestra en qué situaciones el juez ha de sancionar. Como podemos comprobar, el sistema es consistente, puesto que no hay soluciones normativas incompatibles entre sí y, en virtud del principio de legalidad, también completo, dado que no existen casos en los que quede indeterminado qué hacer respecto de la imposición de la sanción penal: en todos los supuestos es claro si ha de absolverse o de condenarse (y, en este último caso, por qué delito).

El problema que interesa a Alonso aparece en el apartado 3 de su contribución, cuando nos muestra que el sistema del ciudadano, esto es, el subconjunto de normas que regula la conducta de los ciudadanos respecto de un específico universo de discurso, presenta una colisión de deberes. Éste se concreta en la situación de quien, en proceso concursal, es intimado al pago, fuera de las reglas del concurso, de un cheque rechazado. ¿Cuál es el deber del ciudadano? Por un lado, y según el artículo $176.3^{\circ}$ del Código penal Argentino, el sujeto no puede efectuar pagos fuera de las reglas de concurso; por otro, conforme el artículo $302.1^{\circ}$ del mismo texto legal, intimado al pago de un cheque rechazado, ha de efectuar tal pago en el plazo de 24 horas.

La situación resulta problemática desde el punto de vista pragmático porque nos resulta inconcebible que la orientación que el ciudadano recibe del sistema jurídico sea del tipo: "hagas lo que hagas estás condenado", y esto es precisamente lo que según Alonso sucede en 
el caso. Sin embargo, ¿realmente es esto lo que le dice el sistema jurídico al ciudadano en el caso? Entiendo que no. El Código penal argentino no sólo contiene normas de mandato o prohibición, sino que también prevé normas que excluyen la sanción de conductas que sin su existencia serían sancionadas. En el caso que nos ocupa resulta del máximo interés el art. 34 de tal Código penal, que sin grandes precisiones dogmáticas indica que "no son punibles" una serie de conductas, entre las que se incluye la de "El que causare un mal por evitar otro mayor inminente a que ha sido extraño" $\left(3^{\circ}\right)$. Estamos ante la regulación del estado de necesidad, una causa de justificación que, en opinión ampliamente mayoritaria, incluye la colisión de deberes ${ }^{6}$. Se trata de una disposición de la parte general del Código penal tendencialmente aplicable a cualquier delito y que califica deónticamente como permitida toda conducta que cumpla con los requisitos que establece ${ }^{7}$.

Lo que Alonso necesita para justificar su caracterización de los sistemas del juez y del ciudadano es una explicación de por qué deja de considerar unas normas, las relativas a la justificación, que son válidas, vigentes, aplicables y del mismo rango que las previstas en los

${ }^{6}$ En un principio Alonso parece entender que la colisión de deberes es un supuesto de cumplimiento de un deber, eximente recogida en el inciso $4^{\circ}$ del artículo 34 (v. p. 48, nota 20), si bien luego se refiere a ésta como un supuesto de estado de necesidad (p. 55). Entiendo que esta última caracterización dogmática es la correcta, una opinión compartida por la doctrina argentina mayoritaria (RIGHI 2002: 54; ZAFFARONI/ ALAGIA/SLOKAR 2000: 474 -si bien estos últimos autores se apartan de este consenso-). En lo que sigue partiré de que ésta es también la opinión de Alonso.

${ }^{7}$ Existe un salto entre afirmar que algo "no es punible" (como hace el art. 34 del Código penal argentino) y que su calificación deóntica es la de conducta permitida. Según el entendimiento ampliamente mayoritario, las conductas antijurídicas pero excusadas y las conductas antijurídicas y culpables que caen bajo una causa de exclusión de la punibilidad tienen la calificación deóntica de prohibidas, y sin embargo no son punibles. Así, para quienes en algunos supuestos el estado de necesidad es una causa de exclusión de la culpabilidad, no será cierto que la conducta en cuestión esté permitida: simplemente su autor no será sancionado. Como se advirtió en las dos notas anteriores, tanto Alonso como yo entendemos que la colisión de deberes es un subconjunto del estado de necesidad y que tiene efecto justificante incluso cuando los deberes en colisión poseen el mismo rango. Esta última es una opción discutida, pero siendo compartida por Alonso y por mí, su discusión puede quedar para otro momento. 
artículos $176.3^{\circ}$ y $302.1^{\circ}$ por él escogidos. Por supuesto, Alonso puede construir los subconjuntos normativos que quiera (y por eso afirmo que su especificación del sistema del juez y del ciudadano es inadecuada, no errónea). Es perfectamente posible construir un conjunto integrado por los números pares, Jhering y Savigny ${ }^{8}$. Sin embargo, uno se pregunta para qué pueda servir construir semejante conjunto. Del mismo modo, tampoco se ve la utilidad de construir un subconjunto de normas que deja fuera algunas normas válidas, vigentes y aplicables al caso, cuya toma en consideración obliga a solucionar el supuesto en sentido distinto del que lo hace el subconjunto escogido por Juan Pablo Alonso (y en el mismo sentido al que finalmente llega Alonso tras aplicar la colisión de deberes).

En el sistema construido por Alonso los jueces se encuentran ante la obligación de sancionar al sujeto tanto si paga como si no paga el cheque, y ello genera un conflicto al ciudadano del caso, que por imperativo lógico tiene que llevar a cabo una de estas dos conductas. Sin embargo, en el subsistema jurídico-penal argentino realmente aplicable al caso, la colisión de deberes opera de modo tal que ex ante facto tanto el juez como el ciudadano saben que, de cumplir con el deber más importante (si es que alguno prevalece), el sujeto quedará exento de responsabilidad. Ningún abogado argentino que sepa de la existencia de la institución de la colisión de deberes le dirá a un cliente que se encuentre en la situación analizada que haga lo que haga el juez tendrá la obligación de sancionarle. Lo que le dirá es que, si cumple el deber más importante (en caso de equivalencia, cualquiera de ellos), su conducta estará justificada y por lo tanto tendrá la calificación de permitida. Que la especificación de los sistemas del juez y del ciudadano de Alonso no dé cuenta de esta calificación deóntica, cuando ésta se puede hacer fácilmente, muestra su inadecuación.

No es fácil entender qué sentido tiene indagar las contradicciones que surgen de la puesta en común de dos subsistemas cuyos elementos son escogidos por el propio autor cuando el problema surge precisamente por no incluir en ellos una norma, la que establece el carácter justificante de la colisión de deberes, que forma parte del

\footnotetext{
${ }^{8}$ El ejemplo es de HernándeZ MARín (1982: 41).
} 
sistema jurídico argentino. Se prescinde de tal norma para luego hacerla aparecer como un deus ex machina que solventa el "conflicto". ¿Por qué no incluir la colisión de deberes en la definición de los sistemas del ciudadano y del juez, disolviendo el conflicto? A mí no se me ocurre ni un solo motivo por el que no hacerlo, y por esta razón entiendo que la construcción que se nos presenta es innecesaria y, en cierto modo, perturbadora, en cuanto genera la impresión de que existe un conflicto pragmático donde éste realmente no se da: ex ante facto tanto el juez como el ciudadano saben que la conducta consistente en el cumplimiento del deber más importante tiene la calificación deóntica de permitida. ¿Por qué fingir que está primero prohibida y luego permitida?

Como el lector habrá podido observar, la situación recuerda a la discusión sobre la relación entre el tipo y la antijuridicidad en Derecho penal, y concretamente en torno a la viabilidad de la denominada "teoría de los elementos negativos del tipo". En otro lugar he dedicado unas pocas decenas de páginas a esta polémica, desarrollada con más calor que luz durante los últimos 80 años, mostrando los errores conceptuales cometidos por ambos polos de la discusión (ORTIZ DE URBINA 2008). Aquí me limitaré a ofrecer un resumen de los extremos de dicha discusión que tienen incidencia sobre el tema que nos ocupa.

El efecto de las causas de justificación puede explicarse entendiendo que éstas excluyen las normas directivas "correspondientes" o que introducen nuevas definiciones en tales normas. En el primer caso (exclusión), se afirma que en los casos en los que se dan las condiciones para aplicar tanto una norma directiva o prohibitiva determinada (por ejemplo, la norma prohibitiva que se extrae del tipo penal que define el homicidio) como una norma permisiva (por ejemplo la legítima defensa), la segunda norma excluye la aplicación de la primera ${ }^{9}$. En el segundo caso (redefinición), se afirma que la situación

\footnotetext{
${ }^{9}$ El principio de especialidad es el criterio habitual de resolución de conflictos entre normas cuando éstas se encuentran en una relación de subordinación en el sentido que KLUG (1956) dio al término, es decir, cuando los supuestos que caen dentro del ámbito de aplicación de la norma $X$ siempre caen así mismo dentro del ámbito de aplicación de la norma $Y$, sin que lo contrario sea cierto. Para una clara explicación de las relaciones normativas de heterogeneidad, interferencia y subordinación adelantadas por Klug, v. HRUSCHKA (1988: 387396, especialmente 389-392).
} 
de colisión generada a partir de la concurrencia de la norma directiva con la permisiva se resuelve entendiendo que los presupuestos de la permisión se incorporan a la norma directiva en forma de "elementos negativos", redefiniendo por tanto su ámbito de aplicación (este parece ser el procedimiento seguido por la teoría de los elementos negativos del tipo en su versión mayoritaria, que suele afirmar que el tipo del homicidio ha de leerse como una prohibición de matar salvo que concurran circunstancias eximentes, que forman parte de la definición del homicidio como elementos "negativos" cuya presencia impide su apreciación $)^{10}$.

Frente a lo que ha entendido la dogmática penal de influencia alemana, la decisión sobre si las causas de justificación desplazan a las prohibiciones o se integran en éstas como elementos negativos no se resuelve mediante sesudas investigaciones sobre los principios fundamentales del Derecho penal, sino de un modo más prosaico: atendiendo a la técnica legislativa efectivamente utilizada.

Las normas son -en el caso de las leyes- el resultado de la interpretación de los enunciados aprobados por el legislador. Tal y como apunta LuZón (1996: 299), el legislador en ocasiones evita el conflicto normativo incluyendo las excepciones dentro del propio enunciado de la norma de mandato. Un ejemplo de lo anterior lo encontramos en el código penal español, cuando en las detenciones ilegales y secuestros realizados por autoridad o funcionario (art. 167) se emplea la expresión "fuera de los casos permitidos por la Ley". Si la detención se hace dentro de los casos legales, simplemente no se cumple con la descripción del delito de detenciones ilegales hechas por autoridad o funcionario, sin necesidad de acudir al cumplimiento de un deber como causa de justificación. El legislador podría introducir las causas de justificación

\footnotetext{
${ }^{10}$ El mismo procedimiento (exclusión/redefinición) puede seguirse en todos los casos en los que dos normas se refieren al mismo supuesto de hecho disponiendo consecuencias jurídicas incompatibles, de modo que la discusión no se restringe al ámbito jurídico-penal, ni en éste al de la antijuridicidad, sino que es más general. Este extremo fue puesto de manifiesto en la obra de MiNASVON SAVIGNY (1972: 3-6). Incomprensiblemente (dado que la obra es muy citada, y por lo tanto es de suponer que también ha sido muy leída), tanto este extremo como otras importantes aportaciones de dicha obra son rutinariamente ignorados en el tratamiento de la cuestión.
} 
como parte de la definición de cada uno de los delitos: después de describir los elementos que actualmente caracterizan el delito de que se trate, se establecería que la pena correspondiente se impondrá salvo que concurran los elementos definitorios de las distintas causas de justificación. Así, de considerar el legislador que el estado de necesidad es de aplicación en el tipo del art. 176, inciso $3^{\circ}$, éste quedaría de la siguiente manera:

Será reprimido, como quebrado fraudulento, con prisión de 2 a 6 años e inhabilitación especial de 3 a 10 años, el comerciante declarado en quiebra que, en fraude a sus acreedores, hubiere incurrido en alguno de los hechos siguientes:

$\cdots$

$\left.3^{\circ}\right)$ Conceder ventajas indebidas a cualquier acreedor, excepto cuando ello se hubiera hecho para evitar un mal mayor inminente a que ha sido extraño.

El problema es que el "excepto cuando" del anterior ejemplo tendría que referirse no sólo al estado de necesidad, sino a todas las causas de exención de responsabilidad penal, lo que resultaría en tipos penales muy extensos y repetitivos. Por razones de economía legislativa, entonces, este procedimiento no es el más usual. En los ordenamientos jurídicos modernos normalmente se prefiere establecer un catálogo de eximentes de aplicación tendencialmente general a todos los delitos. En los ordenamientos en los que esto es así, entre los que se encuentran tanto el argentino como el español y el alemán, la conducta justificada se puede incluir - prima facie, si se quiere- tanto en el supuesto de hecho de la norma de mandato/prohibición como en el de la norma de permiso (un homicidio justificado en legítima defensa cae tanto dentro de la norma que prevé el homicidio como de aquella que prevé su justificación cuando se dan ciertos requisitos). Se produce por tanto una colisión normativa ${ }^{11}$, que se solventa otorgando prelación al precepto especial, esto es, al que prevé la causa de justificación ${ }^{12}$.

\footnotetext{
${ }^{11}$ Muy claros en este sentido, HruschKA (1980: 121-122); KINDHÄUSER (1989: 107-111).

${ }^{12}$ Como afirma KLug (1956: 69-70), el criterio de especialidad no tiene carácter lógico, ya que de las relaciones formales entre enunciados no puede inferirse
} 
¿Qué relevancia tiene el anterior análisis? En sí mismo, y de nuevo frente a lo que se ha venido pensando en la discusión en torno a la teoría de los elementos negativos del tipo, ninguna. Pero sí sirve para poner de manifiesto un aspecto importante de la motivación a través de normas penales:

Desde el principio, no se prohíbe genéricamente matar, sino sólo matar en las situaciones $\mathrm{A}, \mathrm{O}, \mathrm{C}(\ldots)$ lo que ocurre es que la motivación de la norma no se dirige a evitar hechos típicos, sino hechos antijurídicos o, en otras palabras, se dirige a evitar hechos típicos salvo en los casos en que la realización de esos hechos tiene lugar en una situación de justificación (SILVA, 1992: 360, énfasis añadido).

Según esta concepción, que comparto, en términos pragmáticos no se pretende motivar a la evitación de hechos típicos, sino a la de hechos antijurídicos ${ }^{13}$. Si adoptamos la perspectiva del sujeto que actúa, para él "desde el principio" su conducta está permitida, toda vez que cuando comienza a actuar el ordenamiento jurídico ya ha resuelto por medio del principio de especialidad el conflicto entre las dos normas, y lo ha hecho en favor de la permisión de su conducta. Al sujeto que actúa el ordenamiento jurídico no le ofrece una doble calificación

que el principio de especialidad sea preferible a un hipotético "principio de generalidad". Sin embargo, su adecuación y su utilidad en el ámbito de la razón práctica (no sólo en el Derecho) están fuera de toda duda, ya que la especialidad garantiza que las descripciones más precisas de las acciones, las que más elementos han tenido en cuenta, sean las que predominen.

${ }^{13}$ En este mismo sentido, LUZÓN (1996: 299): “Según esta concepción el tipo penal no tiene por misión describir conductas neutras, ni meramente indiciarias de una prohibición pero que realmente pueden resultar valoradas positivamente y permitidas, sino que su función es que la ley describa, para conocimiento general y para cumplir su función de norma de determinación de las conductas de los ciudadanos, todos los elementos, positivos y negativos, que fundamentan la valoración negativa y consiguiente prohibición general -frente a todos- de una conducta, y ello sólo sucede si en la misma no concurren causas de justificación". En el planteamiento de LuZón resulta criticable la vinculación de la justificación penal a la valoración positiva de la conducta: para que tenga sentido justificar una conducta es suficiente con que ésta no sea merecedora de una valoración global negativa. 
deóntica (primero prohibido/luego permitido), sino sólo una. Su conducta está desde el inicio de su actuación permitida, y no "primero prohibida pero luego permitida": quien es agredido y emprende una acción defensiva no lleva a cabo "primero" una acción prohibida y "luego" una permitida, ya que desde el momento en que comienza a defenderse el ordenamiento jurídico anuda una única calificación deóntica a su actuación: la permisión. Así pues, podemos decir que desde el punto de vista normológico, desde el principio y hasta el final, hay dos normas, mientras que desde el punto de vista pragmático el sujeto recibe un único mensaje normativo puesto que la norma especial (en este caso el permiso) desplaza a la general (la prohibición).

Esta dimensión pragmática es la razón por la que no se entiende que Alonso prescinda de las normas de permiso en su descripción de los sistemas del juez y del ciudadano.

Según el sistema del ciudadano que se nos propone, el sujeto tiene que decidir entre (a) pagar un cheque, y ser condenado por infracción de las reglas del concurso, y no pagarlo, y (b) ser condenado por un delito de impago de cheque. La realidad, sin embargo, es que el sujeto se encuentra en situación de colisión de deberes, y en estos casos el ordenamiento jurídico ex ante facto y de modo general prevé la exclusión de responsabilidad si se cumple el deber más importante (y, lógicamente, prohíbe al juez sancionar). Cuando se dan los presupuestos de dicha causa de justificación esta actúa como norma especial, desplazando la aplicación de la norma de mandato. En el caso propuesto por Alonso, de pensarse que estamos ante deberes equivalentes, como él hace (y yo no, pero esta cuestión se analiza en el siguiente apartado), habría que concluir que ya en el sistema del ciudadano la calificación deóntica de su actuación es, haga lo que haga, la de permitida. Si el ciudadano decide pagar el cheque, el art. 34.3 del Código penal desplazará a la disposición contenida en el art. $176.3^{\circ}$, mientras que, si decide no pagarlo, el mismo art. 34.3 desplazará al art. 302.1º en ambos casos por ser norma especial respecto de cualquiera de ellos puesto que, además de sus respectivos elementos (que el art. 34.3 incluye por remisión, al referirse a los "males"), incluye aquellos que aluden a la existencia de una situación de necesidad. La simple inclusión del art. 34.3 del Código penal en la descripción del sistema del ciudadano acaba 
con la perplejidad pragmática en la que la descripción propuesta por Alonso nos sumía: tras su inclusión, el sistema del ciudadano y el del juez son coherentes. La perplejidad ahora es otra: ¿por qué no se ha incluido el art. 34.3 en la determinación de las obligaciones del juez y del ciudadano?

\section{LA CONCRETA RESOLUCIÓN DEL CONFLICTO}

Hasta aquí se ha analizado lo que entiendo que es una deficiente especificación de los sistemas del juez y del ciudadano por la indebida omisión de las normas que contienen circunstancias eximentes, y en concreto del art. 34.3 del Código penal argentino, que tipifica el estado de necesidad/la colisión de deberes. Pero no acaban aquí los problemas de la contribución que se analiza. Una vez determinado que en el caso concreto estamos ante un supuesto de colisión de deberes, Alonso concluye que el sujeto en ella inmerso quedará exento de responsabilidad haga lo que haga, esto es, cumpliendo cualquiera de los deberes. Ello sería así porque, según Alonso, es imposible asegurar que uno de los dos tipos penales en conflicto imponga un deber de mayor rango que el otro.

Yo voy a afirmar lo contrario: el tipo contenido en el art. 176, inciso $3^{\circ}$ establece un deber superior al establecido por el art. 302, inciso $1^{\circ}$, y por lo tanto el sujeto sólo quedará exento de responsabilidad cumpliendo con ese deber.

La cuestión es puramente dogmática: cómo ha de procederse en la determinación de la jerarquía entre deberes penales. Hay supuestos que resultan muy complejos, pero enseguida mostraré que éste no lo es. No voy sin embargo a profundizar en el posible problema que puede suponer la ausencia de previsión legal específica de la obligación de cumplir con el deber más importante. En primer lugar, porque Alonso no lo hace (lógicamente, dado que entiende que los deberes en conflicto son equivalentes por no poder argüirse justificadamente la primacía de uno de los dos) y, en segundo lugar, porque la colisión de deberes se conceptualiza como un subconjunto del estado de necesidad, y en los casos en los que hay dos deberes en conflicto quien elige cumplir el 
menos gravoso estaría incumpliendo el presupuesto de la institución: que exista una situación de necesidad ${ }^{14}$.

Alonso lleva a cabo su análisis de la jerarquía de los dos deberes en colisión en el apartado 5.2 de su trabajo. En éste se centra en mostrar que en realidad no puede afirmarse que alguno de los dos deberes en juego prevalezca sobre el otro. Para ello comienza por intentar rebatir el argumento más común, que podríamos denominar "cuantitativo", según el cual, para determinar qué deber jurídico es más importante, ha de atenderse a las consecuencias de su infracción: el deber más importante será el establecido por el precepto que prevea una sanción más elevada. A continuación, efectúa un análisis más cualitativo de los bienes jurídicos protegidos por ambas normas, para concluir que estamos ante "bienes jurídicos distintos que apuntan hacia principios distintos (la propiedad, por un lado; el libre mercado, por el otro), y es difícil, sino (sic) imposible, determinar cuál de ellos debe prevalecer en desmedro de otro" (p. 54).

a.- Comenzaré por esta última conclusión. Los bienes jurídicos protegidos por los tipos de los que extraemos las normas en colisión son sin duda dispares, pero en absoluto presentan una disparidad mayor que otros muchos supuestos de estado de necesidad. Así, no veo razón alguna para entender que la distancia cualitativa entre la propiedad y el libre mercado sea mayor que la existente entre la propiedad y la vida (sujeto que tiene que romper una ventana ajena para acceder a la habitación en la que su hijo se está asfixiando) o la libertad ambulatoria y la vida (sujeto que inmoviliza a otro, ebrio, que camina hacia un precipicio). Por el contrario, creo que en el caso que se nos presenta estamos ante bienes jurídicos cualitativamente muy similares.

Alonso entiende que el bien jurídico protegido por el delito de cheque en descubierto es el libre mercado, y aporta referencias doctrinales en tal sentido. A mí tal calificación me resulta, como poco, incompleta. Sin duda el sistema financiero (y traslaticiamente el libre

\footnotetext{
${ }^{14}$ El acuerdo doctrinal al respecto lo resumen ZAFFARONI/ ALAGIA/SLOKAR (2000: 602): "La necesidad juega un papel central en la legítima defensa, en el estado de necesidad justificante y en la exclusión de la culpabilidad. En los tres supuestos, el concepto no varía: se entiende que media necesidad cuando el agente no dispone de otro medio menos ofensivo para evitar la lesión" (énfasis suyo).
} 
mercado) puede verse afectado por el impago de cheques y la pérdida de fiabilidad de tal medio de pago. Sin embargo, no creo que pueda dudarse de que el impago del cheque también afecta al patrimonio del acreedor, de modo que puede afirmarse que existe una referencia individual en el bien jurídico colectivo protegido ${ }^{15}$. Y viceversa: el delito concursal puede proteger el patrimonio del deudor, como dice Alonso (aunque es claro que lo hace instrumentalmente, para proteger el de los acreedores). Sin embargo, al proteger la prelación de créditos en los concursos al mismo tiempo se protege la confianza en los procedimientos concursales, lo que sin duda también protege el libre mercado. Es decir: en este caso el bien jurídico que se caracteriza como individual también tiene una vertiente colectiva. A fin de cuentas, ambos bienes protegen el mismo bien jurídico individual (el patrimonio de los acreedores) y el mismo bien jurídico colectivo (el libre mercado, a través de la confianza en ciertas instituciones básicas de la economía de mercado).

b.- Como se ha visto, no creo que los bienes jurídicos en conflicto sean cualitativamente distintos. Sin embargo, precisamente porque en otros casos pueden serlo es por lo que en aras de la objetividad se acude al criterio de la pena con la que se protegen dichos bienes. Alonso, sin embargo, presenta diversas objeciones a este proceder:

“no puede afirmarse que 'no matar' es más importante que ‘no dañar el patrimonio’ porque el primero está penado más severamente que el segundo, sino lo contrario: porque la vida es más importante que el patrimonio es que 'matar' tiene mayor pena que 'dañar el patrimonio"' (p. 51).

Este argumento no apoya la posición de Alonso, sino que, al contrario, concede la mayor: que los intereses (bienes) más importantes se protegen con penas más elevadas y que, si esto es así, la existencia de

\footnotetext{
${ }^{15}$ Según ha mostrado recientemente KUHLEN (2006: 154-155), la caracterización de un concreto bien jurídico puede ser objeto de muchas manipulaciones. Sin embargo, la caracterización que he hecho es exactamente la que impera en el Derecho penal español. En éste, después de 1995, el impago de cheques dejó de ser un delito autónomo para integrarse como una agravante específica del delito de estafa $\left(\operatorname{art} .250 .1^{\circ} 3^{\circ}\right.$ ), un delito cuyo principal objeto de protección es el patrimonio.
} 
una pena más alta permite inferir la existencia de un bien (en nuestro caso un deber) más importante. Ello se ve bien si trasladamos la retórica de la argumentación expuesta al caso que nos ocupa:

No puede afirmarse que "la obligación de respetar las reglas del concurso" es más importante que "la obligación de pagar los cheques que uno extiende" porque lo primero está penado más severamente que lo segundo, sino lo contrario: porque la protección del patrimonio es más importante que la protección del libre mercado es que "no respetar las reglas del concurso" tiene mayor pena que "no pagar los cheques que uno extiende.

Como decía, con su argumento Alonso concede la mayor: es porque el patrimonio es más importante que el libre mercado que el artículo $176.3^{\circ}$ prevé una pena mayor que el art. 302.1 ${ }^{\circ}$. Así pues, podemos comparar el valor relativo de los deberes que ambos preceptos imponen para la protección de los bienes subyacentes y concluir que el deber establecido por el $176.3^{\circ}$ ha de considerarse más importante.

c.- Tampoco parece acertada la alusión de Alonso a la existencia de supuestos en los que bienes jurídicos importantes se protegen de manera alternativa al sistema penal. Tales supuestos efectivamente existen, pero no parece que resulten muy relevantes para el caso que nos ocupa, dado que no estamos ante un supuesto en el que uno de los dos bienes se proteja sólo extrapenalmente en atención al principio de ultima ratio y por existir mecanismos extrapenales que protegen suficientemente el bien en cuestión. En este supuesto, por el contrario, el legislador ha decidido proteger ambos bienes mediante el establecimiento de deberes cuyo incumplimiento se sanciona penalmente, de modo que lo que ocurra en esos otros casos es, sin un ulterior razonamiento, irrelevante.

Mejores argumentos habría encontrado Alonso de haber tirado del hilo que le ofrecía Claus Roxin en unas afirmaciones por él citadas (p. 51): en ocasiones la magnitud de la pena "está esencialmente codeterminada por las modalidades de ataque". Ello es cierto, y pondré dos ejemplos de situaciones en las que esto ocurre.

En primer lugar, cuando los tipos difieren en cuanto a sus condiciones de imputación subjetiva. Los delitos dolosos prevén penas 
superiores a los imprudentes, de modo que el que el delito de estafa tenga en el ordenamiento jurídico español una pena superior al homicidio por imprudencia leve, no significa que en el ordenamiento jurídico-penal español el patrimonio se considere un bien jurídico más importante que la vida, sino que se explica en atención a la diferente modalidad de ataque (dolosa/imprudente $)^{16}$.

En segundo lugar, puede ocurrir también que dos tipos con iguales exigencias en cuanto a la imputación subjetiva (dos tipos dolosos, pongamos) difieran en cuanto a la gravedad del ataque al bien jurídico. En ocasiones los tipos hacen referencia a la necesidad de que el ataque al interés protegido sea "grave", o rebajan tal requisito a "leve". En estos casos también pueden producirse diferencias penológicas que no tienen que ver con el valor del bien en sí, sino con la intensidad con la que éste es atacado. El ejemplo de las lesiones resulta particularmente ilustrativo: todos los delitos de lesiones protegen el bien jurídico "indemnidad física y psíquica", pero sus penas varían considerablemente en atención al alcance de la lesión de tal bien jurídico. Algunos tipos de lesiones tienen penas menores que algunos delitos que protegen la propiedad. Sin embargo, los tipos más graves de lesiones tienen penas mayores que los delitos contra la propiedad con más pena.

En casos como los señalados, decía, es posible que la diferencia de pena se explique por factores distintos del valor de los bienes jurídicos en cuestión. Sin embargo, el argumento, correcto en general, no sirve en el caso que nos ocupa, dado que los tipos previstos en los artículos $176.3^{\circ}$ y $302.1^{\circ}$ comparten forma de imputación subjetiva (son ambos dolosos) y ninguno establece requisitos especiales en cuanto a la entidad de la lesión del bien jurídico.

d.- El último argumento de Alonso para negar que en el caso exista un deber superior a otro tiene que ver con la pena explícitamente prevista:

las diferencias entre las escalas penales de los delitos analizados (el de quiebra y el de cheque) no son significativas; de hecho

\footnotetext{
${ }^{16}$ Lo mismo ocurre cuando uno de los tipos en cuestión es de peligro y el otro es de resultado: tampoco en este caso tendría sentido la comparación porque no se está ante el mismo grado de lesividad para los bienes jurídicos en juego.
} 
comparten gran parte de la escala penal, situación que debilita aún más el argumento (p. 51).

El argumento resulta manifiestamente implausible. El tipo previsto en el art. 176.3 prevé una pena de prisión de 2 a 6 años y una inhabilitación especial de 3 a 10 años, mientras que el previsto en el art. $302.1^{\circ}$ establece una pena de prisión de 6 meses a 4 años y una inhabilitación especial de 1 a 5 años. A mí, incluso a primera vista, me parece claro que hay diferencias relevantes entre una y otra combinación de penas. Sin embargo, la psicología cognitiva nos muestra que los seres humanos somos un pequeño desastre cuando tenemos que comparar sucesos de poca probabilidad o magnitud, por lo que resulta oportuno acudir a la matemática: el mínimo de la pena de prisión prevista en el primero de los preceptos es cuatro veces superior al del segundo, mientras que el máximo de esa misma pena de prisión es un $50 \%$ superior. Si nos fijamos en la pena de inhabilitación especial, el mínimo es tres veces superior y el máximo dos veces superior. En estas condiciones, resulta por completo inadecuado afirmar que las diferencias no son significativas, y por completo irrelevante el que las penas compartan parte (en ningún caso "gran parte", dado que es menos del $50 \%$ ) de la escala penal. Si la cuestión todavía no resulta clara, pruébese a multiplicar ambas magnitudes por cinco. En tal caso tendríamos dos penas, una de 10 a 30 años de prisión y 15 a 50 años de inhabilitación y otra de 2 años y medio a 20 años de prisión y de 5 a 25 años de inhabilitación. ¿Se observan diferencias relevantes? Claro que sí, y son proporcionalmente las mismas que se dan entre las penas realmente previstas por los preceptos que nos interesan.

A la misma conclusión llegamos desde la perspectiva del sujeto, un criterio al que en ocasiones recurre el legislador (no es inusual que los códigos prevean que en casos de duda sobre la norma más favorable se dé audiencia al reo). En un momento de su artículo (p. 43) Alonso escribe que en la situación que nos ocupa "pagar o no pagar el cheque se torna irrelevante; toda vez que, pague o no pague, procederá la sanción penal". Para no cometer una petición de principio dando por probado aquello que me interesa probar, a efectos estrictamente dialécticos partiré de que efectivamente pagar y no pagar el cheque 
tienen la misma calificación deóntica (ambas cosas estarían prohibidas). Incluso bajo este supuesto, sin embargo, pragmáticamente pagar o no pagar el cheque no es en absoluto "irrelevante": si paga, el sujeto enfrentará una condena de prisión de 2 a 6 años y una inhabilitación especial de 3 a 10 años, mientras que si no paga tendrá que arrostrar una pena de prisión de 6 meses a 4 años y una inhabilitación especial de 1 a 5 años. Pagar o no pagar el cheque es por lo tanto relevante. Incluso bajo el supuesto, entiendo que inadecuado, de que el sistema del ciudadano le indica a éste que haga lo que haga incurrirá en responsabilidad, ningún abogado competente aconsejará a su cliente que pague, dado que ello le supondría una mayor pena, tanto privativa de libertad como restrictiva de derechos. Puede que a Alonso-académico la diferencia entre una y otra pena no le parezca significativa. Pero estoy seguro de que Alonsociudadano no comparte su criterio.

Por supuesto, Alonso puede seguir insistiendo en que el legislador se ha equivocado a la hora de establecer las penas. Pero creo que tal protesta debe entenderse como una propuesta lege ferenda. Dogmáticamente, cuando hablamos de la primacía de un deber sobre otro no nos referimos a nuestra opinión al respecto, sino a cuál ha sido la decisión (expresa o implícita) del legislador. En este supuesto, y no habiendo diferencias en cuanto a la imputación subjetiva (ambos tipos son dolosos) ni especiales indicaciones sobre la intensidad de la lesión necesaria, la diferencia entre las penas establecidas no deja lugar a dudas sobre cuál de estos deberes es más importante en el subsistema jurídicopenal argentino: el establecido por el art. $176.3^{\circ}$.

En conclusión: frente a lo afirmado por Alonso, en el supuesto analizado nos encontramos ante una colisión de deberes de distinto rango, en la que el sujeto afectado sólo puede eludir responsabilidad penal cumpliendo el deber de mayor jerarquía, que en este caso es el de respetar las reglas concursales de pago.

\section{OBSERVACIÓN FINAL}

Toca concluir. Soy un confeso admirador de la aplicación de la teoría analítica del Derecho para la resolución de problemas jurídico- 
penales llevada a cabo por Juan Pablo Alonso en la que fue su tesis doctoral, "Interpretación de las normas y derecho penal", y, de modo más general, un firme partidario del uso de este tipo de utillaje conceptual en la elaboración jurídico-penal. En esta ocasión, sin embargo, y por las razones que se han expuesto, su aportación no me resulta convincente.

Las contribuciones de la teoría analítica del Derecho a la resolución de concretos problemas jurídico-penales, si bien existentes y en mi opinión fecundas, no son legión. Aplicar dicho aparato teórico donde éste no mejora en ningún sentido la aportación de la dogmática no va a contribuir a convencer a los penalistas de su utilidad. De hecho, probablemente tenga un efecto desalentador inverso, tanto más preocupante en cuanto se produce en un ámbito del conocimiento, el de la dogmática jurídico-penal, caracterizado por la resistencia a las visiones alternativas y la tendencia a considerar como competidoras formas de análisis que realmente son complementarias. 


\section{Bibliografía:}

Cuerda Riezu, A.: "El concurso real y la acumulación de penas en la STS 197/2006, del 28 de febrero, relativa al caso Henri Parot. Observaciones legales y constitucionales", Nuevas posiciones de la dogmática jurídico-penal, Cuadernos de Derecho Judicial, Consejo General del Poder Judicial, VII2006, pp. 215-226.

DíEZ RIPOLLÉs, José Luis: "Exigencias sociales y política criminal”, en Claves de Razón Práctica, septiembre de 1998, pp. 48-53.

DomÈNECH, Antoni: "Ocho desiderata metodológicos de las teorías sociales normativas", en Isegoría № 18, mayo de 1998, pp. 115-141.

GARZÓn VALDÉS, Ernesto: "Prólogo" a Las claves del derecho, de Daniel Mendonça. Gedisa, Barcelona, 2000, pp. 11-17.

Glock, Hans-Johann: What is Analytic Philosophy?. Cambridge University Press, Cambridge (RU), 2008.

HERnÁndez MARín, Rafael: "Dogmática y Sociología jurídica: sobre la ontología del conocimiento jurídico", en: Mir Puig (ed.): Derecho Penal y Ciencias Sociales, Volumen I, Bellaterra, 1982, pp. 33-52.

HruschKA, Joachim: "El objeto del juicio de antijuridicidad según el Derecho penal actual. Sobre la consistencia de las posibles concepciones acerca de los errores relativos a las circunstancias de hecho", en Sánchez-Ostiz (ed.): Joachim Hruschka. Imputación y Derecho penal. Estudios sobre la teoría de la imputación. Aranzadi, Cizur Menor (Navarra) 2006, (publicado originalmente en 1980, fecha por la que se cita), pp. 101-125.

HRUSCHKA, Joachim: Strafrecht nach logisch-analytischer Methode. $2^{a}$ ed. Walter de Gruyter. Berlín/Nueva York, 1988. 
KINDHÄUSER, Urs; Gefährdung als Straftat. Rechtstheoretische Untersuchungen zur Dogmatik der abstrakten und konkreten Gefährdungsdelikte. Vittorio Klostermann, Frankfurt a.M., 1989.

KLUG, Ulrich: "Sobre el concepto de concurso de leyes. (Análisis lógico de una regulación lingüística de la dogmática penal)", en el mismo: Problemas de la filosofía y de la pragmática del derecho. Alfa, Barcelona 1989, pp. 55-73 (publicado originalmente en 1956, fecha por la que se cita en el texto).

KuHLEN, Lothar: "Rechtsgüter und neuartige Deliktstypen", en von Hirsch/Seelmann/Wohlers (eds.): Mediating Principles. Begrenzungzprinzipien bei der Strafbegründung. Nomos, Baden-Baden, 2006, pp. 148-156.

LuZón Peña, Diego Manuel: Curso de Derecho penal. Parte General I. Universitas, Madrid, 1996.

Minas-Von Savigny, Jutta: Negative Tatbestandsmerkmale. Ein Beitrag zur Rechtssatz- und Konkurrenzlehre. Carl Heymanns. Colonia et al, 1972.

Mir PUIG, Santiago: "Derecho Penal", en Ferreiro/Miquel/Mir/Salvador (eds): La enseñanza del derecho en España. Tecnos, Madrid, 1987, pp. 178-187.

Righi, Esteban: Antijuricidad y Justificación. Lumiere, Buenos Aires, 2002.

Robinson, Paul H.: Distributive Principles of Criminal Law. Who Should Be Punished How Much? Oxford University Press, Oxford 2008.

Roxin, Claus: Strafrecht Allgemeiner Teil. Band I. $4^{\mathrm{a}}$ ed. Beck, Munich, 2006.

Silva SÁnchez, Jesús-María: Aproximación al Derecho penal contemporáneo. José María Bosch, Barcelona, 1992.

Thagard Paul R.: "The Best Explanation: Criteria for Theory Choice". Journal of Philosophy 75 (2):76-92. 
Iñigo Ortiz de Urbina Gimeno

Zaffaroni, Eugenio Raúl/Alagia, Alejandro/Slokar, Alejandro: Derecho Penal. Parte General. Ediar. Buenos Aires, Argentina, 2000. 